\title{
Artigo
}

\section{Edições de literatura indígena no Brasil: visibilidades e opacidades}

\author{
Editions of indigenous literature in Brazil: visibilities and opacities
}

\author{
Marta Aparecida Pereira da Rocha Costa' \\ 'Centro Federal de Educação Tecnológica de Minas Gerais, Minas Gerais, MG, Brasil
}

\section{RESUMO}

Este estudo analisa a leitura de duas edições de autoria indígena, editadas e publicadas no Brasil. O objetivo foi observar se essas edições seriam percebidas como sendo edições indígenas e se teriam alguma visibilidade, questões sobre o gênero, a autoria e a produção desses livros. Dois grupos de dez alunos cada receberam edições indígenas diferentes para manusear, observar os paratextos e registrar por escrito as suas percepções sobre essas edições. Os resultados demonstraram que os livros não foram percebidos como edições indígenas na sua materialidade. Também não foram percebidas a existência da autoria indígena e da literatura indígena ${ }^{1}$. Neste estudo, o livro indígena foi definido com base em Almeida (2004) e Almeida (2009), e os aspectos referentes à visibilidade mediada embasados em Thompson (2008) e Thompson (2013).

Palavras-chave: Edições indígenas; Literatura indígena; Livro; Livro indígena

\section{ABSTRACT}

This study analyzes the reading of two editions of indigenous authorship, edited and published in Brazil. The objective was to see if these issues would be perceived as indigenous issues and have some visibility questions such as gender and authorship. Two groups of ten students each received different indigenous issues to handle, observe the paratexts and writing their perceptions about these issues. The results showed that the books were not perceived as indigenous issues in its materiality. They were not perceived the existence of indigenous authorship and indigenous literature. In this study, the indigenous book was defined based on Almeida (2004) and Almeida (2009), and aspects relating to mediated visibility based in Thompson (2008) and Thompson (2013).

Keywords: Indigenous Issues; Indigenous literature; Book; Indigenous book

\footnotetext{
1 Esses resultados foram apresentados no XII Jogo do Livro, evento bianual realizado em novembro de 2017 pelo Gpell/Ceale - UFMG, dedicado à literatura e reflexão do texto poético entre as diferentes linguagens. No contexto deste periódico esses resultados buscam contribuir para uma reflexão crítica sobre a visibilidade de edições indígenas como produtos de um processo editorial.
} 


\section{INTRODUÇÃO}

A proposta deste artigo nasceu de uma inquietação após a leitura, em dezembro de 2015, dos textos de Almeida (2009) sobre livros de literatura indígena e em terras indígenas. Livros "com cara de índio", como diz a autora. O que seria livro "com cara de índio"? Seriam livros artesanais, manuscritos e ilustrados com tintas orgânicas? Estariam restritos ao espaço das aldeias ou seria possível ter acesso a um exemplar em alguma biblioteca ou livraria, física ou virtual? Almeida (2009) refere-se a um movimento literário e a uma experiência de autoria nas aldeias desde 1979 e ao constatar isso minha questão começou a desdobrar-se. Como são esses livros? Por que não estão nas livrarias? Por que não se encontram nos estandes das editoras em feiras de livros? Haveria alguma visibilidade para essas obras? Como seriam planejados e produzidos? Foram muitas as questões que se apresentaram. Optei por investigar e buscar compreender as possíveis visibilidades ou opacidades dessas edições. Seria, o livro indígena, uma edição fácil de se reconhecer como tal? Seriam, de fato, livros "com cara de índio"? Seria, ainda, a literatura indígena, um gênero fácil de se reconhecer nesses livros em um primeiro contato com eles? Estariam visíveis, na perigrafia ${ }^{2}$ dessas edições, possíveis respostas para essas questões? Definidas as questões, o próximo passo foi conhecer as edições indígenas na sua materialidade. Procurei por exemplares em livrarias e também sites de vendas de livros, novos e usados, pela Web. Essa procura durou três semanas até que localizei dois títulos na Biblioteca Universitária da Faculdade de Letras da Universidade Federal de Minas Gerais (UFMG), os quais apresentarei mais adiante, na metodologia.

\section{LIVRO E A ESCOLA INDÍGENA}

Para que se tenha uma noção sobre o que são edições indígenas no Brasil é preciso colocar algumas informações apuradas e que passo a apresentar aqui. A

\footnotetext{
${ }^{2}$ Na concepção de Almeida e Queiroz (2004), são textos introdutórios que fazem parte das edições indígenas.
} 
atual população indígena no Brasil, verificada pelo censo de 2010 e disponível no portal da Fundação Nacional do Índio (FUNAI) é de 896 mil indivíduos, sendo que 517 mil vivem em terras indígenas oficialmente reconhecidas. Em estudo sobre o livro indígena, Lima (2012) afirma que esses vêm sendo escritos desde o fim da década de 1970, mas "só agora os povos indígenas do Brasil estão escrevendo em suas línguas e publicando suas histórias" (LIMA, 2012, p.17). Sobre publicar suas histórias, Pizarro (2012) acrescenta que a escrita indígena já não precisa de intermediários. Na literatura indígena já "não existe mais o escritor que interpreta, representa, reivindica ou traduz suas palavras; não há mais a antiga necessidade do antropólogo ou intelectual que autorizava a palavra indígena" (PIZARRO, 2012, p. 225).

Um fator foi decisivo para alavancar a edição de livros indígenas no Brasil. Em 2008, a Lei de número 11.645/2008 criou a obrigatoriedade de se tratar da temática "História e Cultura Afro-Brasileira e Indígena" no âmbito de todo o currículo escolar, especialmente nas áreas de educação artística, história e literatura. A partir dessa publicação estava criada uma demanda escolar por uma literatura indígena impressa e que antes existia basicamente na sua oralidade. Em estudos sobre a experiência literária em terras indígenas, Almeida (2009) nos dá uma ideia do desafio que deveria ser enfrentado.

Era preciso transcrever as línguas indígenas para que fosse possível o registro de uma literatura própria dos povos e essa transcrição não poderia ser feita sem o pleno conhecimento dessas línguas. Dessa forma, falantes das línguas indígenas, além da língua portuguesa, professores indígenas, intelectuais e líderes comunitários passaram a escrever e publicar em suas línguas nativas e também em Língua Portuguesa. Os livros produzidos auxiliaram os professores indígenas em seu desafio de ensinar às crianças a ler e escrever nas aldeias.

Estudo de Almeida (2004) sobre edições da narrativa oral no Brasil registrou a existência de mais de 1.500 escolas indígenas, muitas delas bilíngues. São esses professores, afirma a autora, que estão construindo a literatura de suas comunidades, em grande parte das escolas indígenas. Tão singular quanto a escola 
indígena, algumas estruturadas em ocas de alvenaria nas aldeias (figura 1), é o livro de autoria indígena, como explica Almeida (2004).

No espaço de representação do livro indígena, uma imagem que prevalece é a da aldeia. Na maioria dos livros publicados pelos índios, o signo da aldeia encontra espaço privilegiado de circulação. Para os índios, é na aldeia que se encontra a sua única possibilidade de sobrevivência, quer como grupo, etnia, quer individualmente (ALMEIDA, 2004, p. 222).

Trata-se, o livro indígena, de uma escritura coletiva. Não é um ou mais autores que escrevem o livro indígena, mas toda a comunidade, principalmente os mais velhos. São eles que narram as histórias transcritas pelos tradutores. Juntos narram seus mitos em edições que registram suas línguas, a história de seus povos, o cotidiano das aldeias e revelam ao mundo sua literatura. Dessa forma, os indígenas, "ao criarem seu sistema escolar, alfabetizando as crianças nas suas próprias línguas, estão criando as condições para o desenvolvimento de suas poéticas da escrita" (ALMEIDA, 2004, p. 277).

Figura 1 - Escola da reserva Pataxó da Jaqueira em Porto Seguro - BA

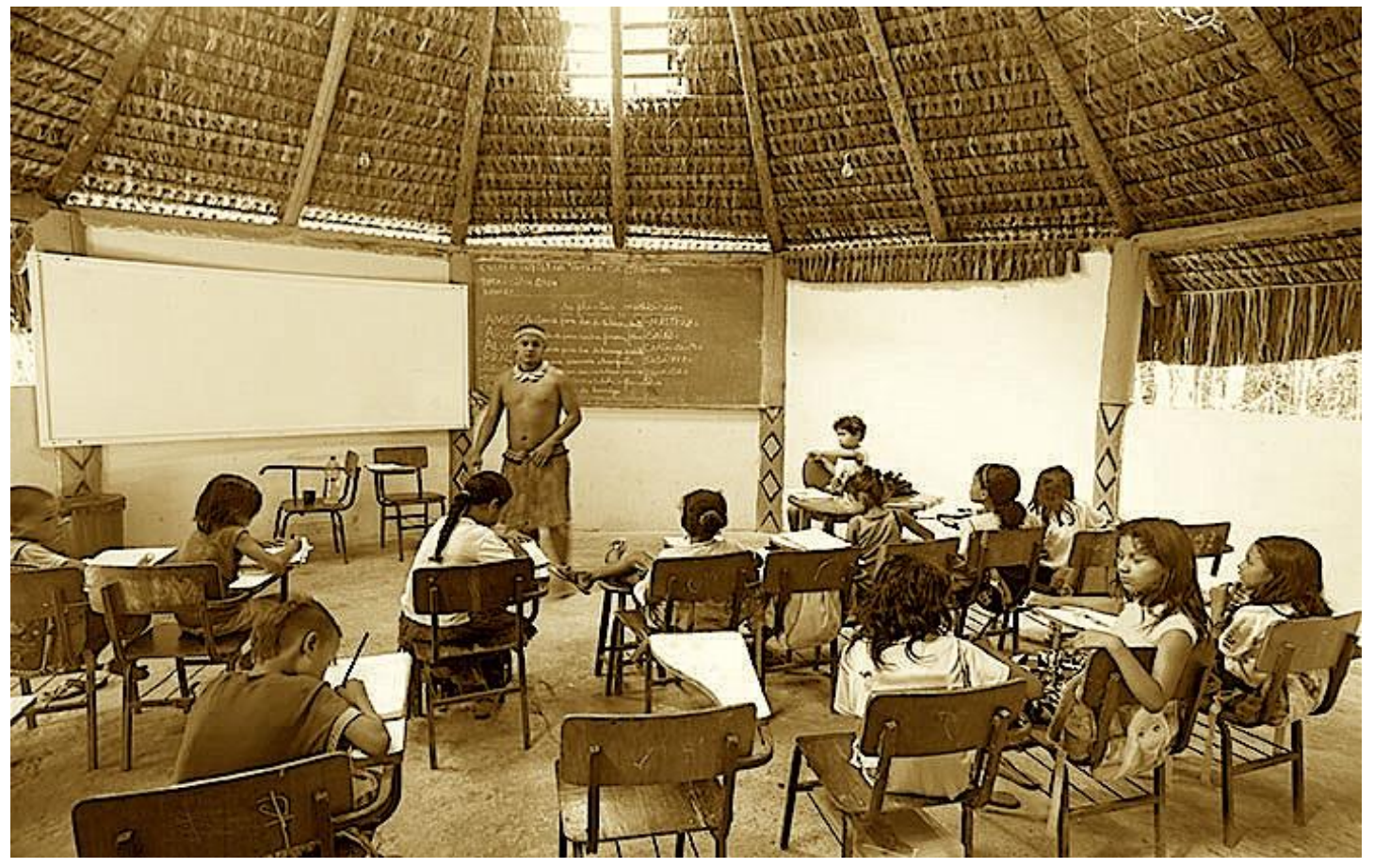

Fonte: Renato Soares. Imagens do Brasil (2016). 


\section{FUNDAMENTAÇÃO TEÓRICA}

O conceito de visibilidade com o qual trabalhei neste estudo foi dado por Thompson (2008) em um ensaio sobre a nova visibilidade mediada. Thompson (2008) afirma que a visibilidade das pessoas, suas ações e acontecimentos é situada, mas também livre. Este conceito me pareceu pertinente para a análise que pretendia realizar por contemplar, além da visibilidade dos indivíduos, também a visibilidade de suas ações, no caso, a edição de livros indígenas planejados, escritos, ilustrados e publicados por eles mesmos. Diz esse autor acerca da visibilidade:

Aqueles que são visíveis para nós são os que compartilham a mesma situação espácio-temporal. A visibilidade é também recíproca (ao menos por princípio): nós podemos ver outros que estão dentro do nosso campo de visão, mas eles também podem nos ver (considerando que não estejamos ocultos de alguma forma). É a visibilidade situada da co-presença. No entanto, com o desenvolvimento da comunicação mediática a visibilidade está livre das propriedades espaciais e temporais do aqui e agora. A visibilidade das pessoas, suas ações e acontecimentos estão libertos do compartilhamento de um solo comum (THOMPSON, 2008, p. 20).

A nossa percepção do visível estaria assim, segundo Thompson (2008), libertada de uma condição espaço-temporal para se manifestar. Logo, não faria sentido dizer que não conheço determinadas edições por que foram publicadas em alguma aldeia no interior de uma floresta e em determinado tempo histórico, uma vez que a comunicação mediática tornaria possível esta visibilidade. Em outro estudo, agora sobre as edições comerciais nos Estados Unidos e no Reino Unido, Thompson (2013) reconhece que a visibilidade é algo que custa caro. Paga-se muito para que determinadas edições sejam notadas dentro das livrarias. Além disso, a publicidade nos meios de comunicação de massa já não ajudaria tanto a vender livros. Os esforços para se conquistar a visibilidade naqueles mercados se concentram hoje na divulgação de livros por meio de e-mails, sites e blogs. Partindo desses pressupostos, busquei compreender a existência de uma possível visibilidade das edições indígenas na sua materialidade; mediada por livros impressos em primeiro lugar, e depois por meio das 
micromídias³ ${ }^{3}$ para usar aqui uma expressão do próprio Thompson (2013). Reiterando, o que busquei ao longo deste estudo foi descobrir como o leitor percebe tais objetos de leitura, o que poderia demonstrar, ou não, alguma visibilidade das edições indígenas como tal. Afinal, existiriam livros indígenas "com cara de índio"? Ou esse traço de identidade existiria apenas em seu conteúdo e seriam, por assim dizer, livros com alma de índio?

\section{METODOLOGIA}

Minha opção por analisar edições indígenas do gênero literatura e não didáticos, por exemplo, se deu devido ao fato de serem mais acessíveis. Até a finalização deste artigo ainda não havia visualizado, nem impresso e nem na Web, um exemplar de livro didático indígena. Outra razão foi a curiosida de sobre que narrativas os indígenas estariam projetando para fora de suas aldeias, frente ao que diz Pizarro (2012) ao afirmar que atualmente, "uma mudança fundamental está ocorrendo no campo dos imaginários, pois os indígenas começam a escrever e publicar seus próprios textos, para conhecimento do grande público" (PIZARRO, 2012, p. 225).

O primeiro passo foi listar os títulos de edições indígenas citados nos estudos de Almeida (2004 e 2009) e tentar adquiri-los em sites de vendas de livros, mas nenhum título foi encontrado disponível para venda. Em seguida, tentei acessá-los em bibliotecas digitais, novamente sem sucesso. Localizei dois títulos na Biblioteca Universitária da Faculdade de Letras da UFMG, e solicitei o empréstimo desses exemplares para este estudo. O primeiro exemplar intitula-se Encontros Traduções, (figura 2), de autoria de professores indígenas da tribo Xacriabá e publicado em 2009 pela editora FALE/UFMG. Encontros Traduções traz dez narrativas escritas e ilustradas por autores indígenas. O Segundo exemplar intitula-se Com os Mais

\footnotetext{
3 Thompson (2013) se refere à micromídia como sendo sites, blogs ou mesmo listas de e-mails, a qual ele apresenta como alternativa para a divulgação de livros frente à tradicional comunicação de massa.
} 
Velhos, (figura 3), também de autoria dos Índios Xacriabá e publicado em 2005 pela editora FALE/UFMG. Essa edição traz vinte e quatro narrativas de autores indígenas, narrativas essas que foram gravadas, transcritas, digitadas, revisadas e editadas por professores indígenas com a participação de estudantes e pesquisadores das áreas de letras, música, artes cênicas e artes plásticas da UFMG.

Figura 2 - Capa da edição Encontros Traduções, de autoria dos Índios Xacriabá

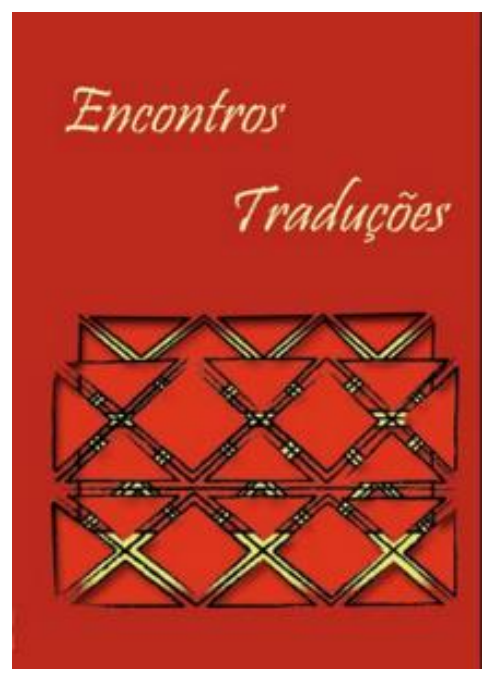

Fonte: Literaterras (2016).

Figura 3 - Capa da edição Com os mais velhos, de autoria dos Índios Xacriabá

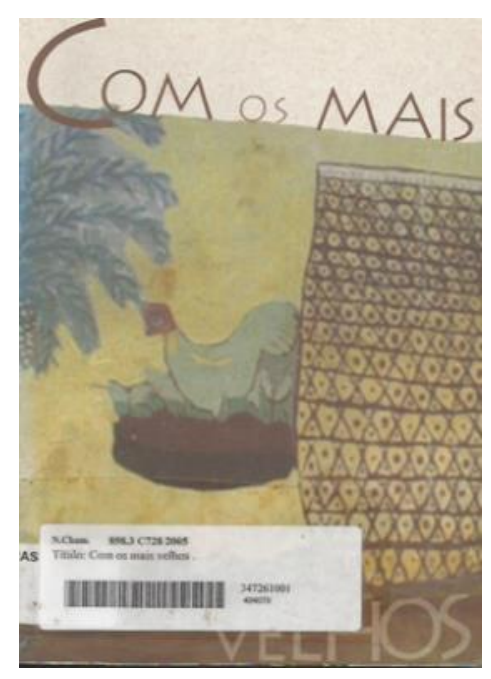

Fonte: Imagem da capa escaneada pela autora. 
Definidos os objetos de análise passei à coleta de dados. Preparei um formulário simples, composto por uma única questão precedida de algumas instruções. Após ler essas instruções, o leitor participante deveria manusear a edição e registrar, de forma simples e em frases curtas, quais teriam sido as suas primeiras percepções sobre o livro. Para tanto deveriam observar as informações verbais e não verbais presentes na capa, contracapa e paratextos. Esses formulários foram submetidos a vinte alunos do segundo período do curso de Letras de uma escola pública federal. Dez alunos trabalharam com o livro Encontros Traduções e outros dez com o livro Com os mais velhos. O tempo da coleta dos dados estendeu-se pelo período de duas aulas seguidas, considerando que cada leitor participante deveria manusear o exemplar, observar e registrar por escrito suas percepções. Esses leitores foram identificados aqui como sendo L1, L2, L3, e assim sucessivamente. Após a coleta, os dados foram organizados para a análise que apresentamos a seguir.

\section{ANÁLISES E RESULTADOS}

\subsection{Visibilidade mediada pelo livro impresso}

Antes de dar início à análise, observei cada exemplar e listei os elementos verbais e não verbais, presentes nas duas edições. No caso, elementos que apresentaram algum indício sobre o caráter indígena das edições. Verifiquei que havia informações sobre a autoria indígena nas fichas catalográficas e folhas de rosto. Também nessas fichas estavam indicados o gênero literatura indígena e os nomes dos povos indígenas autores. Organizei essas observações no quadro 1, na ordem em que elas se apresentaram. Em seguida organizei, no quadro 2, os 
elementos que se mostraram visíveis e opacos ${ }^{4}$ na observação dos leitores participantes.

Quadro 1 - Informações verbais e não verbais sobre o caráter indígena das edições

\begin{tabular}{|c|c|}
\hline Livro 1 & $\begin{array}{l}\text { - Grafismo étnico apresentado na capa, contracapa e na } \\
\text { - } \text { perigrafia da edição. } \\
\text { texto e ilustraçãões de Creuza Nunes Lopes Xacriabá, } \\
\text { primeira entrada de assunto: Índios Xacriabá, segunda } \\
\text { entrada: Índios Pataxó, Terceira entrada: Literatura } \\
\text { Indígena. } \\
\text { - } \quad \text { Folha de rosto traz a expressão “Professores Indígenas”. } \\
\text { - O verso da folha de rosto lista os dez colaboradores que } \\
\text { trabalharam textos e ilustrações da edição. Todos eles } \\
\text { trazem os sobrenomes indígenas Xacriabá e Pataxó. } \\
\text { - O último título apresentado no sumário está escrito em } \\
\text { língua indígena com tradução para o português. } \\
\text { - Grafismo ético, o mesmo da capa, impresso ao lado da } \\
\text { página que traz a apresentação do livro. } \\
\text { - Na apresentação, primeiro parágrafo, somos informados de } \\
\text { que a obra resultou de trabalhos realizados durante um } \\
\text { curso de formação intercultural para professores indígenas. }\end{array}$ \\
\hline Livro 2 & $\begin{array}{l}\text { - Acima da ficha catalográfica estão listadas as instituições } \\
\text { que colaboraram para a edição. Entre elas, a Organização } \\
\text { da Educação Indígena Xacriabá - OEIX. } \\
\text { - Ficha catalográfica indicando: a autoria dos Índios Xacriabá, } \\
\text { pesquisa de professores Xacriabá, primeira entrada de } \\
\text { assunto: Índios Xacriabá, segunda entrada: Literatura } \\
\text { Indígena - Brasil, terceira entrada: Índios Xacriabá - } \\
\text { História, quarta entrada: Índios Xacriabá - Usos e costumes. } \\
\text { - Folha de rosto traz a expressão “Povo Xacriabá” na margem } \\
\text { superior. } \\
\text { - O verso da folha de rosto lista sessenta professores } \\
\text { indígenas que trabalharam na pesquisa, gravação, escrita e } \\
\text { transcriação dos textos. Nesta página também se observa } \\
\text { referência ao apoio da Fundação Nacional do Índio - FUNAI. }\end{array}$ \\
\hline
\end{tabular}

\footnotetext{
${ }^{4}$ Neste texto nos referimos aos elementos opacos como sendo aqueles que apresentam pouca visibilidade para o leitor ou mesmo que não são percebidos por ele.
} 


\begin{tabular}{|l|l|}
\hline - & Na apresentação, primeiro parágrafo, há referência ao \\
& Programa de Implantação das Escolas Indígenas de Minas \\
& Gerais. Também refere-se aos professores indígenas das \\
& tribos Xacriabá, Krenak, Maxacali e Pataxó. \\
- & Após o sumário, em folha isolada, há uma epígrafe de \\
& Emílio Gomes que refere-se ao "viver" do Povo Xacriabá. \\
- & Fotografia em preto e branco com a legenda: “Dona Ercina \\
& Bispo de Santana - Aldeia Brejo Mata Fome”.
\end{tabular}

Fonte: a autora.

Quadro 2 - Elementos visíveis e opacos na observação dos leitores

\begin{tabular}{|l|l|l|l|}
\hline \multicolumn{4}{|l|}{ Elementos visíveis e transparentes nas edições } \\
\hline \multicolumn{2}{|l|}{ Livro 1 } & Opacos & Livro 2 \\
\hline Visíveis & Visíveis & Opacos \\
\hline capa/contracapa & autoria & Capa/contracapa & autoria \\
título & editora & título & $\begin{array}{l}\text { editora } \\
\text { fonte }\end{array}$ \\
sumârio & gênero & papel & gero \\
imagem & propriedade & fonte & eprígrafe \\
papel & patrocínio & apresentação & ano \\
apresentação & grafismo étnico & sumário & ISBN \\
folha de rosto & ano & imagem & empréstimos \\
texto & Isbn & orelha & colofão \\
\hline
\end{tabular}

Fonte: a autora.

\subsubsection{Percepções dos leitores sobre a edição Encontros Traduções}

Dos leitores que manusearam e observaram o livro Encontros Traduções nenhum percebeu a autoria indígena e o gênero literatura indígena, dados na perigrafia da edição, mesmo sem encontrar dificuldades em suas leituras. L3 afirmou que as letras dos paratextos tinham "um formato agradável de ler". Ainda assim, na sua leitura não percebeu a natureza indígena da edição, presente na folha de rosto, ficha catalográfica, apresentação, dentre outros. Já L5 se referiu às informações introdutórias como "bom texto" e L7 como "apresentação didática" sendo que nessa apresentação é dado que a edição resultou da 
formação intercultural de professores indígenas. A edição indígena e sua autoria indígena mostrou-se, portanto, para o grupo de leitores participantes que observou a edição Encontros Traduções, algo transparente em um primeiro contato. A capa mostrou-se o item mais visível. Oito, dentre os dez leitores, se referiram a ela diretamente. L1 afirmou ser "pobre", L2 "sem orelha", L3 "vermelha", L4 "com letras", L7, L8 e L9 como sendo "simples" e L10 como "muito limpa". Ainda que ilustrada com grafismos étnicos, a capa não ofereceu alguma visibilidade ao grupo de leitores sobre o caráter indígena da edição. L7 chegou a dizer que a imagem, apresentada na capa e repetida na contracapa, era "desconexa" e "sem sentido" em relação ao conteúdo interno. Voltaremos e essa percepção de L7 mais adiante.

Sobre as imagens, L1 citou "desenho gráfico inadequado", L2 percebeu os "desenhos simétricos", L5 achou "bem ilustrado", L6 mencionou "desenhos para chamar a atenção", ou seja, os desenhos estavam ali para cumprir uma função e não propriamente por seus significados. Já L7 referiu-se às imagens como "desenho desconexo do conteúdo interno" e também como "sem sentido", não reconhecendo o caráter étnico do grafismo estampado na edição, que pode ser visto aqui na figura 2. Frente a essa percepção de L7 considero oportuno dizer que o grafismo indígena é traço importante e sempre presente na manifestação da identidade das tribos. Em estudo sobre o grafismo indígena, Ribeiro (2012) afirma que as sociedades indígenas reproduzem traços geométricos não apenas como códigos, mas também como "um discurso extra local que situa estes artistasartesãos indígenas no pilar de uma luta pelo reconhecimento étnico" (RIBEIRO, 2012, p. 21). Continuando, L9 afirmou "gostei das ilustrações". Sobre a edição como um todo apenas um leitor L5 apresentou uma percepção mais ampla da obra, ainda que subjetiva. L5 percebeu "um toque de delicadeza e boas aspirações" e ainda como "bem convidativo à leitura". Sua fala não nos permite inferir se houve, ou não, percepção do caráter indígena da edição. Também por meio de suas imagens a Edição indígena observada pelo grupo de leitores participantes permaneceu marcada pela opacidade. Organizei no quadro 3 os elementos não 
percebidos pelos leitores sobre o livro Encontros Traduções e no quadro 4 as percepções individuais dos leitores sobre essa edição.

A observação desta edição de Encontros Traduções revelou-me algo curioso e que compartilho aqui. Trata-se de uma edição publicada em 2009, doada à Biblioteca Universitária em junho de 2013 e até então nunca emprestada para leitores, estudantes, professores ou mesmo pesquisadores. A retirada do exemplar da biblioteca se deu, pela primeira vez, em setembro de 2016 e, em seguida, para fins deste estudo. Isso nos faz pensar sobre a circulação dessas edições também nas bibliotecas. Thompson (2013) coloca uma questão que me parece oportuna aqui: O que estamos fazendo para chamar a atenção dos leitores para o livro? No entanto, essa é uma questão para ser discutida em outro estudo.

Quadro 3 - Elementos não percebidos pelos leitores no Livro 1

\begin{tabular}{|l|l|}
\hline \multicolumn{2}{|l|}{ Elementos não percebidos no Livro 1 - Encontros Traduções } \\
\hline Autoria & Professores Indígenas. \\
\hline Editora & Fale/UFMG. \\
\hline Gênero & Literatura indígena. \\
\hline Propriedade & Biblioteca Universitária da FALE. \\
\hline Publicação & 2009. \\
\hline Patrocínio & Governo Federal. \\
\hline Imagens & $\begin{array}{l}\text { Grafismos étnicos impressos na capa/contracapa e na } \\
\text { apresentação. }\end{array}$ \\
\hline ISBN & Número e código de barras impressos na contracapa. \\
\hline Empréstimos & Uma vez, para fins deste estudo, em 08/09/2016. \\
\hline
\end{tabular}

Fonte: a autora.

Quadro 4 - Percepções individuais dos leitores sobre o livro 1

\begin{tabular}{|c|l|}
\multicolumn{2}{|c|}{ Percepções individuais dos leitores do livro 1 - Encontros Traduções } \\
\hline \multirow{2}{*}{ L1 } & $\begin{array}{l}\text { CAPA: “Capa extremamente pobre”; CONTRACAPA: “Cores desconexas”; } \\
\text { IMAGEM: “Desenho gráfico inadequado"; FONTE: “Fontes não atrativas”. } \\
\text { TÍTULO: “Título desconexo”. }\end{array}$ \\
\hline
\end{tabular}




\begin{tabular}{|c|c|}
\hline $\mathrm{L} 2$ & $\begin{array}{l}\text { CAPA: “Tem uns desenhos simétricos". "Sem orelha”; CONTRACAPA: “de } \\
\text { uma cor diferente da capa”; PARATEXTOS: “O livro tem um sumário e } \\
\text { uma apresentação". "Tem uma Folha de Rosto com o Título”. }\end{array}$ \\
\hline L3 & $\begin{array}{l}\text { CAPA: "A capa do livro, por ser vermelha, se destaca”; CONTRACAPA: } \\
\text { "Traz uma sensação mais alegre, por ser amarela”; FONTE: “As letras do } \\
\text { paratexto são grandes e de um formato agradável”. }\end{array}$ \\
\hline L4 & $\begin{array}{l}\text { CAPA: “Brincadeiras com as letras escritas”; CONTRACAPA: “Cores } \\
\text { chamativas"; PARATEXTO: "Sumário objetivo”. Presença de: instituições, } \\
\text { agradecimentos, formas geométricas e título. }\end{array}$ \\
\hline L5 & $\begin{array}{l}\text { IMAGEM: “Um livro bem ilustrado e bem elaborado”; TEXTO: “Bom } \\
\text { texto"; OBRA: “Tem um toque de delicadeza e boas inspirações”; “Bem } \\
\text { convidativo à leitura”; PAPEL: “Bom material”. }\end{array}$ \\
\hline L6 & $\begin{array}{l}\text { TÍTULO: “Título forte. Título visível”; PARATEXTOS: “Sumário organizado”; } \\
\text { IMAGEM: “Desenhos para chamar a atenção do leitor”. } \\
\text { FONTE: “Letra pequena, mas organizada”; CONTRACAPA: “Contracapa } \\
\text { vaga”. }\end{array}$ \\
\hline L7 & $\begin{array}{l}\text { CAPA: “Capa bem simples”; “Desenho da capa e contracapa desconexo”. } \\
\text { TÍTULO: “Título vago e nada chamativo”; FONTE: “Fontes muito informais, } \\
\text { que não atraem”; PARATEXTOS: “Apresentação didática”; “Sumário muito } \\
\text { marcado”; IMAGENS: “Imagens da capa e contracapa sem sentido”. }\end{array}$ \\
\hline L8 & $\begin{array}{l}\text { CAPA: “A capa é simples"; TÍTULO: “O título não nos diz muito sobre o } \\
\text { que pode conter no livro"; FONTE: "As fontes utilizadas deixam o livro } \\
\text { um pouco 'desleixado"”. }\end{array}$ \\
\hline L9 & $\begin{array}{l}\text { FONTE: “A letra poderia ser maior"; CAPA: “Capa simples”; PAPEL: “Folhas } \\
\text { de boa qualidade”; IMAGENS: “Gostei das ilustrações”. } \\
\text { PARATEXTOS: “Folha de rosto bem feita”; “Sumário bem centralizado”. }\end{array}$ \\
\hline L10 & $\begin{array}{l}\text { CAPA e CONTRACAPA: “O contraste das cores é algo aprisionante”; “O } \\
\text { verniz localizado dá um toque especial à capa”; PAPEL: "A gramatura das } \\
\text { páginas me causou grande estranhamento". }\end{array}$ \\
\hline
\end{tabular}

Fonte: a autora.

\subsubsection{Percepções dos leitores sobre a edição Com os mais velhos}

Dos leitores que manusearam e observaram o livro Com os mais velhos, dois reconheceram tratar-se de uma edição com temática indígena e um terceiro reconheceu que a obra se referia a "um povo que vive num lugar afastado e humilde". Vejamos como se deram essas percepções. L7 afirmou que percebeu, pelo título, que o livro se referia ao passado e que a retomada ao passado foi "em relação ao povo Xacriabá, uma comunidade indígena". Esse leitor não apenas 
identificou a temática indígena da edição como também identificou qual a comunidade indígena à qual se referia, no caso, o povo Xacriabá. O que L1 não percebeu foi que além de tratar de temática indígena o livro também tinha autoria indígena. Sobre o que tratava o livro mostrou-se visível, mas a autoria indígena e a literatura indígena mostraram-se imperceptíveis. L2, observando capa e contracapa, percebeu um contexto, ainda que não muito claro, semelhante "ao mundo indígena". L2 afirmou que os paratextos que observou "são explicativos, vistosos, quase prolíxos ou extenso", mas sua leitura desses textos não foi suficiente para identificar a autoria indígena ou mesmo o gênero literatura indígena. L6 percebeu que o livro tratava "de algo relacionado à natureza e costumes de um povo que vive num lugar afastado e humilde". L6 afirmou que percebeu isso "devido aos desenhos da capa, as cores das folhas e a foto da senhora, no início". A foto da senhora, no caso, é uma composição de três imagens de uma mesma mulher indígena, usando roupas simples e um colar de contas brancas. A foto trazia uma legenda com o nome da senhora Ercina Bispo de Santana e sua localização "Aldeia Brejo Mata Fome". L6, portanto, ao observar a imagem legendada da senhora não suspeitou de que ela pudesse fazer parte de uma comunidade indígena. Para esse leitor as informações na modalidade não verbal articulada ${ }^{5}$ com a verbal não foi suficiente para tornar visível a temática indígena presente na edição. De certa forma, as percepções de $L 7$ e $L 2$, ainda que marcadas pela opacidade, foram as que mais se aproximaram da identidade indígena da edição Com os mais velhos, sem, contudo, reconhecê-la em sua autoria indígena e em sua literatura, também indígena. Antes de seguir apresentando as leituras individuais vejamos, no quadro 5, que elementos não foram percebidos pelos leitores, lembrando que todos estão inscritos na edição.

\footnotetext{
${ }^{5}$ Kress e van Leeuwen (1996) afirmam que diferentes modalidades de linguagens se somam na leitura e construção de significados. Para esses autores imagem e texto trabalham juntos.
} 
Quadro 5 - Elementos não percebidos no Livro 2

\begin{tabular}{|l|l|}
\hline \multicolumn{2}{|l|}{ Elementos não percebidos no Livro 2 - Com os mais velhos } \\
\hline Autoria & Comunidade Indígena. \\
\hline Editora & Fale/UFMG. \\
\hline Gênero & Literatura indígena. \\
\hline Propriedade & Biblioteca Universitária da FALE. \\
\hline Publicação & 2005. \\
\hline Citação & Fala de Emílio Gomes referindo-se ao povo Xacriabá. \\
\hline ISBN & Número e código de barras impressos na contracapa. \\
\hline Colofão & Edições Cipó Voador. \\
\hline Empréstimos & $\begin{array}{l}\text { Quatro vezes, contando com a sua retirada da biblioteca } \\
\text { para este trabalho. }\end{array}$ \\
\hline
\end{tabular}

Fonte: a autora.

Sigo com o meu relato sobre as percepções individuais dos leitores. L1 percebeu no título uma "sensação de tradição", queixou-se da fonte utilizada na apresentação, a qual the pareceu "deslocada". Também referiu-se ao brilho do papel couchê como "incômodo". L3, referindo-se à capa, disse não ser possível "deduzir o conteúdo da obra". Essa percepção vai de encontro à de L6 que percebeu, pela capa, tratar a edição de "algo relacionado à natureza e costumes de um povo". L4, L5, L8, L9 e L10 relataram percepções sobre a materialidade da edição. Sobre a capa, L4 a percebeu como "atraente", L5 como "simples", L9 como "embaçada", L10 como "bem acabada" e L8 percebeu sua ilustração como "obra de arte antiga". Sobre os paratextos, L4 referiu-se à fonte como "atraente" e percebeu a mudança de papel; L5 sentiu falta de texto nas orelhas e percebeu 0 papel reciclado do miolo; L8 se referiu à tipografia como "não-padrão", mas classificou o seu uso como "interessante"; L9 percebeu "todos os textos com a mesma tipografia na folha de rosto e o sumário como "limpo, bem diagramado, com espaçamentos e negrito que facilitam a visualização", e L10 percebeu apenas o sumário como "simples". 
Assim como as percepções de L9 e L10 sobre a capa se mostraram, de certa forma, contrárias, também suas percepções sobre o sumário foram muito distintas. O que L10 percebeu como "simples", para L9 era algo "limpo, bem diagramado, com espaçamentos e negrito facilitando a visualização". Esta percepção de L9 sobre o sumário coincide com resultados de um estudo sobre os elementos da microtipografia em textos. No quadro 6 estão organizadas as percepções individuais dos leitores participantes que manusearam e observaram o livro 2, Com os mais velhos. Também para os leitores desse livro mostrou-se transparente tanto a autoria indígena quanto a literatura indígena. Apenas a temática indígena foi percebida e, mesmo assim, por apenas dois leitores participantes.

Quadro 6 - Percepções individuais dos leitores do Livro 2

\begin{tabular}{|c|c|}
\hline \multicolumn{2}{|r|}{ Percepções individuais dos leitores do Livro 2 - Com os mais velhos } \\
\hline L1 & $\begin{array}{l}\text { CAPA: "reforça a sensação de tradição do título"; FONTE: "fonte da } \\
\text { apresentação destoa do texto interno e parece deslocada"; FICHA: "fácil } \\
\text { entendimento dos dados"; APRESENTAÇÃO: "o brilho do papel couchê é } \\
\text { incômodo". }\end{array}$ \\
\hline $\mathbf{L} 2$ & $\begin{array}{l}\text { CAPA e CONTRACAPA: "remetem a um contexto não tão claro em referência } \\
\text { ao mundo indígena, assemelhando-se ao mundo contemporâneo". } \\
\text { PARATEXTOS: "são explicativos, vistosos, quase prolixo ou extensos, } \\
\text { concorrendo com o conteúdo mais simples". }\end{array}$ \\
\hline L3 & $\begin{array}{l}\text { CAPA: “Ao observar-se a capa do livro não é possível deduzir o conteúdo da } \\
\text { obra. É uma pintura bem rústica que não permite perceber o seu sentido". } \\
\text { IMAGENS: "Nota-se que o livro possui imagens fotográficas e narrativas sobre } \\
\text { acontecimentos reais". }\end{array}$ \\
\hline L4 & $\begin{array}{l}\text { TÍTULO: “Dá ideia do que a história irá abordar”; PAPEL: “Chama atenção por } \\
\text { não ser tão utilizado”; CAPA: “O desenho da capa é atraente”; FONTE: “A letra } \\
\text { escolhida também é atraente”; PARATEXTO: “A parte em que muda-se o } \\
\text { papel, também chama atenção”. }\end{array}$ \\
\hline $\mathbf{L 5}$ & $\begin{array}{l}\text { CAPA: "simples, mas bonita”; ORELHAS: "Sem texto ou qualquer informação } \\
\text { complementar"; PAPEL: "Parece reciclado, bem bonito". }\end{array}$ \\
\hline $\mathbf{L 6}$ & $\begin{array}{l}\text { TEXTO: “O livro trata de algo relacionado à natureza e costumes de um povo } \\
\text { que vive num lugar afastado e humilde"; IMAGEM: percebeu isso "devido aos } \\
\text { desenhos da capa, as cores das folhas e a foto da senhora, no início". }\end{array}$ \\
\hline L7 & $\begin{array}{l}\text { TíTULO: “Através do título do livro ‘Com os mais velhos' percebi que o } \\
\text { conteúdo se trata de algo que retoma o passado"; }\end{array}$ \\
\hline
\end{tabular}




\begin{tabular}{|c|c|}
\hline & $\begin{array}{l}\text { TEMÁTICA: “Percebi que a retomada ao passado é em relação ao povo } \\
\text { xacriabá, uma comunidade indígena”; PAPEL: "O uso da folha reciclada dá um } \\
\text { aspecto amarelado que também relembra história/passado”; CAPA: Utilizou- } \\
\text { se na capa algum tipo de pintura que acredito ter relação com a arte/cultura } \\
\text { do povo estudado". } \\
\text { PARATEXTO: “O sumário me passa uma ideia de percepção do povo estudado } \\
\text { em diversos aspectos, como relação com a terra ou ambiente em que vivem, } \\
\text { forma de tratar enfermidades, muitos mitos e/ou histórias". }\end{array}$ \\
\hline L8 & $\begin{array}{l}\text { CAPA: "Ilustrada com essa obra de arte antiga, conversa bem com o título e } \\
\text { com o material de capa e miolo". TÍTULO: “Colocado de forma interessante". } \\
\text { "A tipografia, bem como a separação da palavra 'velhos' do todo não } \\
\text { valorizam a leiturabilidade". } \\
\text { PARATEXTO: "Essa tipografia se repete nos paratextos. Não é padrão, mas seu } \\
\text { uso é interessantes pela temática". }\end{array}$ \\
\hline L9 & $\begin{array}{l}\text { CAPA: “Deu uma sensação estranha, pois a imagem estava embaçada" } \\
\text { ORELHAS: “Esperava textos nas orelhas" } \\
\text { PARATEXTOS: “Todos os textos com a mesma tipografia”. Sumário "limpo, } \\
\text { bem diagramado, com espaçamentos e negrito que facilitam a visualização". }\end{array}$ \\
\hline L10 & $\begin{array}{l}\text { CAPA: "A capa ilustrada está mais bem acabada"; } \\
\text { PARATEXTO: Sumário "simples, gostei muito". }\end{array}$ \\
\hline
\end{tabular}

Fonte: a autora.

\subsection{Visibilidade mediada pelas micromídias}

Como pontuado aqui, minha prioridade foi observar a percepção dos leitores diante de edições indígenas produzidas por indígenas verificando a visibilidade dessas edições materializadas no livro impresso. Em seguida, busquei sondar a visibilidade dessas edições também nas micromídias por se constituírem "canaischave para o marketing e a publicidade de livros" (THOMPSON, 2013, p. 265). Em minha primeira busca por sites que pudessem hospedar algum conteúdo sobre edições indígenas, sem aspas, encontrei dez resultados dos quais oito eram links para jogos e dois para publicação científica. A busca com a expressão "edições indígenas" entre aspas trouxe, na primeira página, quinze resultados sobre artigos científicos, eventos, editais, apresentações, portal de estudos e também anúncios e notícias. Nenhum link para trechos de edições indígenas em resumos, comentários ou resenhas foi localizado. Busquei também por essas edições nos 
sites de venda de livros, não apenas nos grandes distribuidores como também nos sebos literários e ainda de livros didáticos, sem sucesso. Nos sites de venda de livros a busca foi feita pelo título das edições utilizadas neste estudo. Quanto às bibliotecas digitais, localizei oitenta e três livros em busca sobre literatura indígena na Biblioteca Brasiliana Guitá e José Mindlin, todos eles escritos por autores não indígenas, entre eles Casimiro de Abreu, Machado de Assis e Euclides da Cunha. A busca nessa biblioteca sobre edições indígenas não trouxe resultados. $\mathrm{Na}$ Biblioteca Digital Mundial, a busca por literatura indígena trouxe cinco resultados, nenhum deles para livros. Já a busca por edições indígenas trouxe 48 resultados, dentre os quais 39 fornecidos pela Biblioteca Nacional do Peru. São textos sobre religiões, mitos, artes, dicionários, gramáticas e vocabulários, dentre outros. Nenhum deles de autoria indígena brasileira.

Após utilizar as expressões 'edições indígenas' e 'literatura indígena' para localizar essas publicações, ou mesmo parte delas, retomei a busca, desta vez com a expressão 'livro indígena' em uma tentativa de encontrar algum conteúdo sobre a produção editorial desses objetos de leitura. Dentre os links que encabeçaram a lista dos resultados estavam a Biblioteca Brasiliana Guitá e José Mindlin, o site Educar para crescer, da Editora Abril; o site Carta Educação, que listou um conjunto de dez obras sobre a cultura indígena sendo metade de autoria indígena; o Estante Blog que indicou cinco livros sobre a cultura indígena, sendo três de autoria indígena; o site Povos indígenas no Brasil com downloads de livros de autoria não indígena; o portal da Folha que listou doze edições para crianças, dos quais cinco com autoria indígena; o site da Editora Unesp apresentando edições sobre povos indígenas, mas não de autoria indígena; e, finalmente, o portal da Rádio Yandê com a literatura indígena em uma das abas do menu. Neste portal não apenas a literatura indígena era mostrada como também as autorias de Povo Pataxó, Tupi Guarani, Povo Baniwa, Povo Kaxinawá, Povo Yawanawa e Daniel Munduruku. Sobre os processos de produção editorial indígena: traduções, transcrições, ilustrações, escrita coletiva e impressão, não encontrei registros. 
Foi descobrindo as autorias indígenas e a divulgação que fazem de suas obras, em seus espaços virtuais, que encontrei alguma visibilidade dessas edições na Web. Muitos autores indígenas como Daniel Munduruku, Olívio Jekupe, Graça Graúna e Eliane Potiguara mantêm blogs pessoais e neles publicam seus textos e divulgam a venda de seus livros, como ilustrado pela figura 4. São autores que escrevem individualmente, mas que trazem consigo o eco das vozes de seus povos. Além dos livros de autoria indígena, os blogs divulgam também eventos literários, alguns organizados por instituições públicas o que se observa na figura 5. Há ainda blogs institucionais trabalhando na divulgação de edições indígenas e de suas autorias, como o blog do Núcleo de Escritores e Artistas Indígenas (NEArin), vinculado ao Instituto Indígena Brasileiro para Propriedade Intelectual (IMBRAPI).

Figura 4 - Divulgação de livro indígena pela autora na internet

\section{Adquirir livros}

CLIQUE ABAIXO E VOCÊ TERÁ UMA LISTA DE OPÇÕES ONDE ADQUIRIR O LIVRO:

http://compare.buscape.com.br/metade-cara-metade-mascara-eliane-potiguara8526009435.html\#precos

também:

http://pesquisa.livrariacultura.com.br/busca.php?q=eliane+potiguara

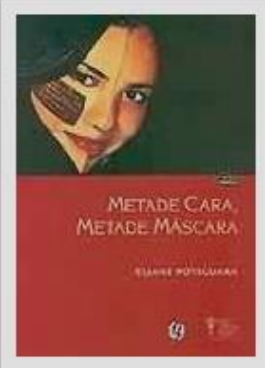

Fonte: elianepotiguara.blogspot.com.br (2016). 
Figura 5 - Convite digital do Primeiro Sarau de Poéticas Indígenas realizado em abril de 2016

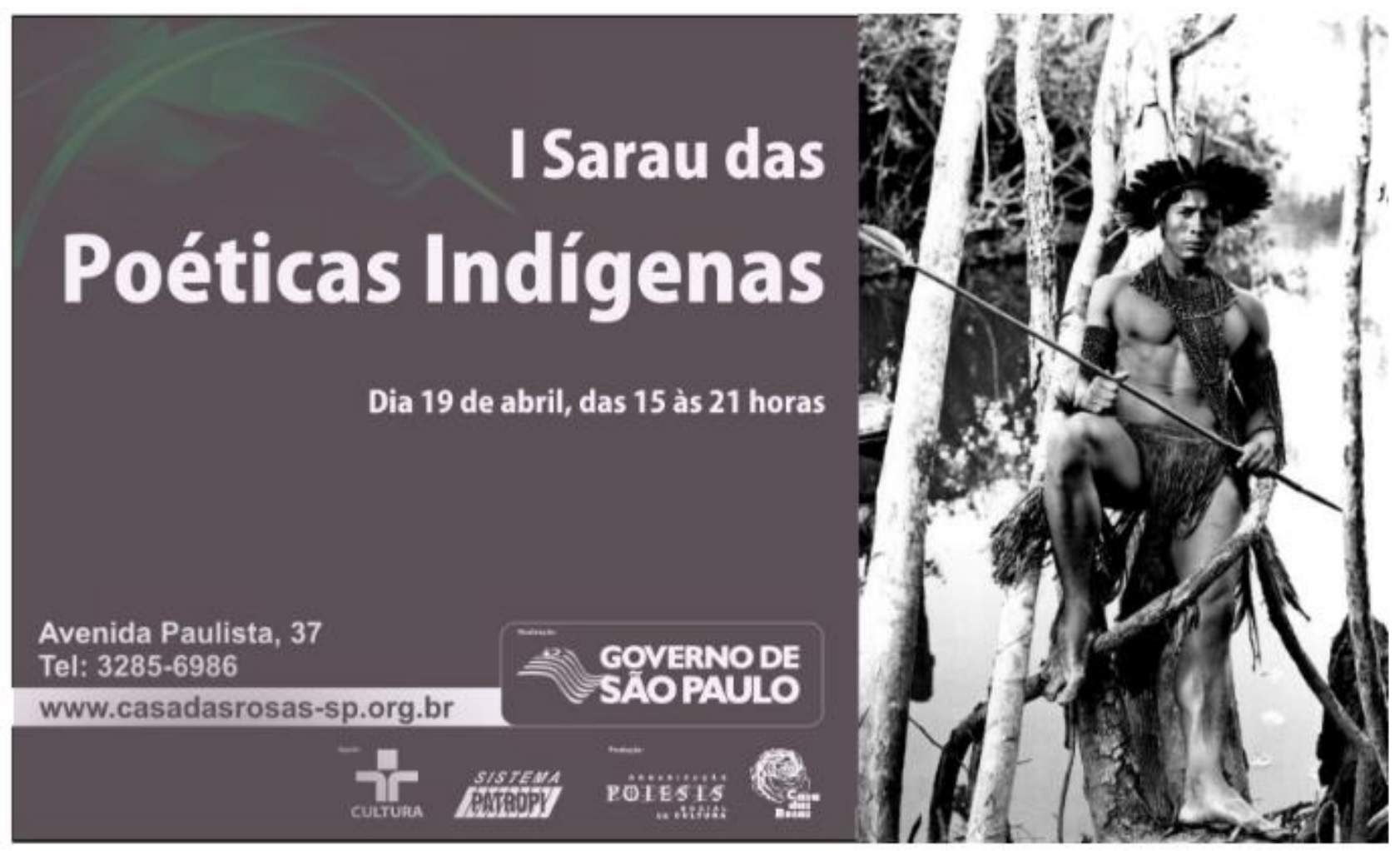

Fonte: Global Voices, (2016).

Fechando essa sessão, seja por meio das mídias comunicacionais às quais se referiu Thompson (2008) acerca da visibilidade mediada, seja por meio das micromídias às quais esse autor se refere no texto de 2013 sobre a publicidade de livros, posso dizer que as edições indígenas e a autoria indígena no Brasil são reais, mas ainda se mostram "imperceptíveis" tanto no livro impresso quanto em espaços como livrarias ou bibliotecas, sejam esses espaços físicos ou virtuais.

\section{CONSIDERAÇÕES FINAIS}

A questão deste estudo foi verificar se o livro indígena seria uma edição assim reconhecida pelos leitores. Se seria possível reconhecer um livro indígena, escrito e editado por indígenas, apenas por meio do contato com ele. No contexto deste breve estudo não o foi. Os leitores que participaram se limitaram a mostrar 
o que viram sobre materialidades como papel, tipografia, imagens, textos e seus diferentes gêneros presentes nas edições de livros como capa, sumário, título, apresentação e folha de rosto. Minha hipótese para isso é o fato de que a identidade indígena impressa nas edições indígenas foi feita por meio da língua portuguesa, mas isso requer estudos mais aprofundados. É fato que a produção de livros por indígenas no Brasil é recente, mas acredito que isso não seja suficiente para justificar o fato de os leitores participantes, alunos de um curso de letras, terem interagido com um produto editorial indígena sem reconhecê-lo como tal. Sobre a possibilidade de serem livros "com cara de índio", este estudo demonstrou serem livros genuinamente indígenas, mas que precisariam ser mais que vistos ou manuseados para terem reconhecida a sua identidade. Precisariam ser lidos, pois é na sua escrita que se inscreve a marca da sua literatura. Seriam, por assim dizer, livros com essência de índio. Os resultados também mostraram que o gênero literatura indígena não foi de fácil reconhecimento para os leitores. Nenhum dos participantes fez qualquer referência às edições analisadas como sendo de literatura indígena. Outra questão foi saber se na perigrafia dessas edições haveria marcas da identidade indígena. Verifiquei essas marcas inscritas nas edições estudadas. Ambas mostram a autoria indígena na folha de rosto, indicam a literatura indígena na ficha catalográfica e fazem referência aos povos indígenas nos textos de apresentação, só para citar as mais importantes.

Thompson (2013) diz que a visibilidade depende do que é mostrado e também falado. É possível construir uma visibilidade boca a boca, afirma o autor. Provavelmente muito mais poderá ser construído e mostrado se esse movimento individual alcançar os espaços da micromídia.

\section{REFERÊNCIAS}

ALMEIDA, Maria Inês. Desocidentada: Experiência literária em terra indígena. Belo Horizonte: Editora UFMG, 2009. 
ALMEIDA, Maria Inês. Na captura da Voz: as edições da narrativa oral no Brasil. Belo Horizonte: Editora Autêntica; FALE/UFMG, 2004.

BRASIL. Lei n. 11.645, de 10 de março de 2008. Torna obrigatório o estudo da história e cultura afro-brasileira e indígena nos estabelecimentos de ensino fundamental e de ensino médio. Brasília, 2008. Legislação Federal.

KRESS, Gunther; LEEUWEN, Theo Van. Reading Images. The Grammar of Visual Design. London: Routledge, 1996.

LITERATERRAS, Núcleo transdisciplinar de pesquisa em tradução, edição e publicação de textos de autoria indígena. Universidade Federal de Minas Gerais, Belo Horizonte, 2016. Disponível em: https://issuu.com/literaterras/docs/livro encontro traducoes. Acesso em: 10 nov. 2016.

PIZARRO, Ana. Amazônia: As Vozes do Rio. Belo Horizonte: Editora UFMG, 2012.

POTIGUARA, Eliane. Divulgação de obra impressa em rede social. Disponível em: http://www.elianepotiguara.org.br. Acesso em: 10 nov. 2016.

RIBEIRO, Maristela Maria. Grafismo Indígena. Trabalho de Conclusão de Curso (Habilitação em Artes Visuais) - Departamento de Artes Visuais, Universidade de Brasília, Brasília, 2012.

ROCHA-COSTA. Marta Aparecida Pereira da. Microtipografia: uma abordagem sobre a recepção de um texto em três diferentes formas de inscrição. Diálogo das Letras, Vol. 4, n. ${ }^{\circ} 2,2015$. Disponível em:

http://periodicos.uern.br/index.php/dialogodasletras/article/view/1786. Acesso em: 8 dez. 2020.

SARAU DAS POÉTICAS INDÍGENAS, 1, 2016, São Paulo. Casa das Rosas.

THOMPSON, John Brookshire. Mercadores de Cultura: o mercado editorial no século XXI. Tradução Alzira Allegro. São Paulo: Editora Unesp, 2013.

THOMPSON, John Brookshire. A Nova Visibilidade. Tradução de Andrea Limberto. Disponível em: www.revistas.usp.br/matrizes/article/download/38190/40930. Acesso em: 19 set. 2016.

XACRIABÁ, Indios. Encontros Traduções; coordenação: Maria Inês Almeida. Belo Horizonte: Editora FALE/UFMG, 2009.

XACRIABÁ, Povo. Com os mais velhos. Belo Horizonte: Editora FALE/UFMG, 2005.

\section{Marta Aparecida Pereira da Rocha Costa}

Mestre em Estudos de Linguagens

https://orcid.org/0000-0002-4138-9708·martarocha@intexto.com.br 